\title{
Meat consumption reduces the risk of nutritional rickets and osteomalacia
}

\author{
Matthew G. Dunnigan ${ }^{1}$, Janet B. Henderson ${ }^{2}$, David J. Hole ${ }^{3 *}$, E. Barbara Mawer ${ }^{4}$ and Jacqueline L. Berry ${ }^{4}$ \\ ${ }^{1}$ University Department of Human Nutrition, Royal Infirmary, Glasgow, UK \\ ${ }^{2}$ Department of Psychiatry, Hairmyres Hospital, East Kilbride, UK \\ ${ }^{3}$ Public Health \& Health Policy, Division of Community Based Sciences, University of Glasgow, UK \\ ${ }^{4}$ University Department of Medicine, Royal Infirmary, Manchester, UK
}

(Received 23 January 2005 - Revised 6 May 2005 - Accepted 20 June 2005)

\begin{abstract}
Endogenous vitamin D deficiency (low serum $25(\mathrm{OH}) \mathrm{D}_{3}$ ) is a necessary but insufficient requirement for the genesis of vitamin $\mathrm{D}$-deficiency rickets and osteomalacia. The magnitude of the independent contributions of dietary factors to rachitic and osteomalacic risk remains uncertain. We reanalysed two weighed dietary surveys of sixty-two cases of rickets and osteomalacia and 113 normal women and children. The independent associations of four dietary variables (vitamin $\mathrm{D}, \mathrm{Ca}$, fibre and meat intakes) and daylight outdoor exposure with rachitic and osteomalacic relative risk were estimated by multivariate logistic regression. Meat and fibre intakes showed significant negative and positive associations respectively with rachitic and osteomalacic relative risk (RR; zero meat intake: RR 29.8 (95\% CI 4.96, 181), $P<0.001$; fibre intake: RR 1.53 (95\% CI 1.01, 2.32), $P=0 \cdot 043$ ). The negative association of meat intakes with rachitic and osteomalacic relative risk was curvilinear; relative risk did not fall further at meat intakes above $60 \mathrm{~g}$ daily. Daylight outdoor exposure showed a significant negative association with combined relative risk (RR $0.33(95 \%$ CI $0 \cdot 17,0 \cdot 66), P<0 \cdot 001)$. Operation of the meat and fibre risk factors was related to sex, age and dietary pattern (omnivore/lactovegetarian), mainly determined by religious affiliation. The mechanism by which meat reduces rachitic and osteomalacic risk is uncertain and appears independent of revised estimates of meat vitamin D content. The meat content of the omnivore Western diet may explain its high degree of protection against nutritional rickets and osteomalacia from infancy to old age in the presence of endogenous vitamin D deficiency.
\end{abstract}

Nutritional rickets: Asian rickets: Rachitic risk factors: Osteomalacic risk factors

Vitamin D-deficient rickets and osteomalacia (adult rickets) occur in settings in which limited skin exposure to UV radiation constrains the photochemical synthesis of cholecalciferol from an inactive precursor (7-dehydrocholesterol; Fraser, 1995). If the diet is largely unfortified, as in the UK, the contribution of dietary vitamin D to vitamin D status is small (Lawson, 1979). The contribution of other dietary factors to the risk of nutritional rickets and osteomalacia remains the subject of debate.

The identification of nutritional rickets and osteomalacia in the Glasgow Asian community in 1962 provided an opportunity to reexamine the relative roles of limited exposure to UV radiation and dietary factors in their aetiology (Dunnigan et al. 1962). Neonatal, infantile, toddler and late rickets in Asian children, and osteomalacia in Asian women, were identified in this small Asian community, and subsequently in most centres of Asian population in the UK (Ford et al. 1972a, 1973; Holmes et al. 1973; Stamp et al. 1980; Iqbal et al. 1994).

Multivariate analysis of a $7 \mathrm{~d}$ weighed case-control study of dietary intakes in eleven rachitic and fourteen normal Muslim omnivore school children indicated that high intakes of dietary fibre and phytate, mainly present as unleavened bread (chapatti), were independent risk factors for Asian rickets in the presence of endogenous vitamin D deficiency (Dunnigan \& Smith, 1965; Dunnigan et al. 1976; Robertson et al. 1982). Multivariate logistic analysis of a second case-control study of weighed dietary intakes and daylight outdoor exposure in rachitic and normal Muslim and Sikh/Hindu children indicated that both high fibre and low or absent meat intakes were significantly associated with late rickets in the presence of endogenous vitamin D deficiency (Henderson et al. 1987). A third case-control study of weighed dietary intakes and daylight outdoor exposure in osteomalacic and normal Muslim and Sikh/Hindu Asian women established that strict lactovegetarianism was the principal independent dietary risk factor for osteomalacia in a context of limited exposure to UV radiation (Henderson et al. 1990). Dietary vitamin D intake did not contribute to rachitic or osteomalacic risk in any case-control study.

These results raise three unresolved questions.

(1) What are the dose-response relationships between meat intake and rachitic and osteomalacic relative risk?

(2) To what extent is the reduction in rachitic/osteomalacic risk associated with meat consumption attributable to revised increased estimates of meat vitamin D content (Chan et al. 1995)?

(3) What is the relationship of the meat and fibre risk factors to age, dietary pattern (omnivore/lactovegetarian) and religious affiliation?

We reanalysed the results of the second rickets and the osteomalacia case-control studies in the light of these issues (Henderson et al. 1987, 1990). The conclusions appear relevant to the aetiology and 
prevention of nutritional rickets and osteomalacia, which remain present in several settings in the developed and less developed world from infancy to old age (Dunnigan \& Henderson, 1997; Wharton \& Bishop, 2003).

\section{Subjects and methods}

The Glasgow Asian community comprises approximately 10000 Asians who originate from the Indian subcontinent, the majority from the Punjab district of India and Pakistan with a minority from East Africa. About $80 \%$ of the community are Muslims, consuming an omnivore diet containing lamb, beef and chicken, mainly in curries, with unleavened flat breads, pulses and cereals. The remaining $20 \%$ of the community are Sikh or Hindu; the majority follow a more lactovegetarian dietary pattern with high intakes of milk, pulses, dhals, vegetables and unleavened flat bread, and small amounts of meat, eggs and fish. A proportion of this population, particularly women, are strict lactovegetarians (Henderson et al. 1990). Both communities consume substantial quantities of refined carbohydrate and their younger members show varying degrees of adaptation to Western dietary patterns.

\section{Composition of the case-control studies}

Group 1: osteomalacia study. This group (Henderson et al. 1990; Table 1) comprised twenty-two Asian women previously discharged from Glasgow hospitals with a diagnosis of nutritional osteomalacia. A further five osteomalacic and seventy-seven normal Asian women were recruited from three general practices in the city.

Group 2: rickets study. This group (Henderson et al. 1987; Table 2) comprised forty-three rachitic and forty-one non-rachitic Asian children recruited from a survey of the prevalence of rickets in an inner-city general practice.

\section{Case definitions}

The epidemiology of rickets and osteomalacia is the study of 'cases' (Dent, 1974). Severe cases of osteomalacia had moderate to severe back and limb pain, with or without a proximal myopathy, and biochemical and X-ray evidence of disease (pseudo-fractures and skeletal demineralisation). Mild cases were asymptomatic or had minor symptoms, with negative X-ray evidence of disease and abnormal pre-treatment corrected serum $\mathrm{Ca}$ and/or phosphate and alkaline phosphatase levels. All cases comprised both mild and severe cases. Asymptomatic women and children without clinical or biochemical evidence of disease were classed as controls. Pre-treatment serum 25(OH)D values were unavailable from most treated cases of rickets and osteomalacia and were not employed in case definitions.

Table 1. Group 1: distribution of female osteomalacia cases and control groups by religion, strict lactovegetarianism and age

\begin{tabular}{lccc}
\hline & \multicolumn{3}{c}{ Osteomalacia: groups } \\
\cline { 2 - 4 } Religion & Controls $(n 77)$ & All cases $(n 27)$ & Severe cases $(n$ 12) \\
\hline Muslim $(n)$ & 52 & 8 & 1 \\
Lactovegetarian $(n)$ & 0 & 1 & 1 \\
Lactovegetarian $(\%)$ & 0 & 13 & 100 \\
Median age (years) & 35 & 35 & 25 \\
Age range (min-max) & $22-58$ & $23-56$ & - \\
Sikh/Hindu ( $n$ ) & 25 & 19 & 11 \\
Lactovegetarian $(n)$ & 6 & 17 & 11 \\
Lactovegetarian $(\%)$ & 24 & 89 & 100 \\
Median age (years) & 38 & 39 & 34 \\
Age range (min-max) & $21-60$ & $20-66$ & $22-66$ \\
M:\% S/H & $68: 32$ & $30: 70$ & $8: 92$ \\
\hline
\end{tabular}

M, Muslim; S/H, Sikh/Hindu.

For details of subjects and procedures, see this page.

Table 2. Group 2: distribution of rickets cases and control groups by religion, age and sex

\begin{tabular}{lccc}
\hline & \multicolumn{3}{c}{ Rickets: groups } \\
\cline { 2 - 4 } Religion & Controls $(n 41)$ & All cases $(n$ 43) & Severe cases $(n$ 16) \\
\hline Muslim $(n)$ & 15 & 14 & 10 \\
Sex (males:females) & $10: 5$ & $6: 8$ & $5: 5$ \\
Median age (years) & 11 & 13 & 15 \\
Age range (min-max) & $7-17$ & $9-16$ & $10-16$ \\
Sikh/Hindu ( $n$ ) & 26 & 29 & 6 \\
Sex (males:females) & $12: 14$ & $15: 14$ & $1: 5$ \\
Median age (years) & 11 & 13 & 13 \\
Age range (min-max) & $7-18$ & $7-17$ & $8-14$ \\
\%:\% S/H & $37: 63$ & $33: 67$ & $62: 38$ \\
\hline
\end{tabular}

M, Muslim; S/H, Sikh/Hindu.

For details of subjects and procedures, see this page. 


\section{Laboratory investigations}

Blood samples were provided by the ninety-one women and eightyfour children who completed $7 \mathrm{~d}$ weighed dietary records for the estimation of serum corrected $\mathrm{Ca}$, phosphate, alkaline phosphatase and serum $25(\mathrm{OH}) \mathrm{D}$. Children and women with abnormal serum biochemistry had X-rays of both knees and of the lumbar spine and pelvic girdle, respectively. Biochemical methods and reference limits employed in previous studies have been published (Dunnigan et al. 1985; Henderson et al. 1990)

\section{Dietary surveys}

Ninety-one of 104 women in Group 1 and all children in Group 2 completed $7 \mathrm{~d}$ weighed dietary intake records with daily records of daylight outdoor exposure. Records were checked daily; in the osteomalacia study the supervising dietician (J. B. H.) was accompanied by an Asian link-worker to assist with translation. Thirteen Asian women (eight cases and five controls) could not complete written records. In these women, a detailed recall dietary history was taken with the help of the Asian link-worker to determine their pattern of dietary intake.

Nutrient intakes were calculated from the computerised food tables of Paul \& Southgate (1978) and the Nutritive Value of Indian Foods (Gopalan et al. 1971). Revised estimates of the vitamin D content of meat were derived from analyses of samples of beef, lamb, veal, pork, chicken and turkey. Based on a relative assessment of the potencies of vitamin D metabolites in a Ca transport assay in the rat (Tanaka et al. 1973), the analyses expressed total vitamin D activity as the sum of the vitamin D and five times the amount of the $25(\mathrm{OH}) \mathrm{D}$ content of the sample (Chan et al. 1995).

\section{Statistical methods}

Based on the results of the two previous case-control studies (Henderson et al. 1987, 1990), the independent associations of four dietary variables with rachitic and osteomalacic risk were reanalysed (meat, fibre, $\mathrm{Ca}$ and vitamin $\mathrm{D}$ intakes). The relationship of meat consumption to rachitic and osteomalacic risk was determined at five levels of daily intake $(0,1-19 \mathrm{~g}, 20-39 \mathrm{~g}, 40-59 \mathrm{~g}$, $60 \mathrm{~g}$ and above). Fibre and $\mathrm{Ca}$ intakes were unchanged from previous analyses. Total dietary vitamin $\mathrm{D}$ intakes were amended to include revised estimates of meat vitamin D. Daylight outdoor exposures for 151 women and children who completed records between September and June were included in the combined rickets and osteomalacia logistic model. A further 105 records of midsummer daylight outdoor exposure in July and August did not contribute significantly to rachitic and osteomalacic risk and were omitted from the final logistic models.

The significance of univariate differences between variables was assessed by the Mann-Whitney $U$ test (two-tailed). The significance of bivariate correlations between variables was assessed by the Spearman non-parametric correlation coefficient (twotailed). The significance of independent associations of the five model variables with rachitic and osteomalacic relative risk was assessed by multivariate logistic regression analysis.

Full details of participants in the case-control studies, dietary food class and nutrient intakes analysed, together with laboratory and statistical methods employed, are available from the original studies (Henderson et al. 1987, 1990). The studies were approved by the Research \& Ethnical Committee of Stobhill General Hospital, Glasgow.

\section{Results}

Group 1: osteomalacia study

Of the control group in the osteomalacia case-control study $32 \%$ were Sikh or Hindu, reflecting the proportion of these religious groups in the practice population surveyed. This rose to $70 \%$ of all cases and to $92 \%$ of severe cases of osteomalacia, reflecting the strong association of a lactovegetarian dietary pattern with osteomalacia. All twelve severe cases, including one Muslim woman, were strictly lactovegetarian (Table 1).

Excluding thirteen women without written dietary records, median meat intakes fell significantly to zero in the all-cases and severe-cases groups compared with the control group. The significant decline in median vitamin $\mathrm{D}$ intakes in these groups compared with controls reflected decreases in meat, fish and egg intakes. A significant rise in median fibre intakes in the severe-cases group and in median $\mathrm{Ca}$ intakes in the severe- and all-cases groups was also associated with the trend to lactovegetarianism with increasing disease severity. Median daylight outdoor exposure was significantly lower in the severe cases group than in the control group (Table 3).

\section{Group 2: rickets study}

A total of $63 \%$ of the control group and $67 \%$ of all cases were Sikh or Hindu, reflecting the proportions of these religious groups in the practice population surveyed. In contrast, $63 \%$ (ten of sixteen) of the severe cases group were omnivore Muslim children. Five of six of the remaining Sikh/Hindu children with severe rickets were strictly lactovegetarian and four had rachitic deformity (genu valgum; Table 2).

A significant decline in median meat intakes between the control and the all-cases and severe-cases groups was accompanied by a significant rise in median fibre intakes in the severe-cases group. Median vitamin D intakes did not fall significantly. Median daylight outdoor exposure was significantly lower in the all-cases and severe-cases groups compared with controls (Table 4).

\section{Multivariate stepwise logistic regression}

The independent associations of dietary variables and daylight outdoor exposure with the relative risk of osteomalacia and rickets, singly and in combination, were measured in four logistic models.

Groups 1 and 2: osteomalacia and rickets model. This combined model (Table 5; Fig. 1) indicated that low and absent meat intakes, high-fibre intakes and low daylight outdoor exposure were significantly associated with rachitic and osteomalacic relative risk. The dose-response relationship of meat intakes to relative risk was curvilinear. The highest significant relative risk was associated with zero meat intakes, with large reductions in relative risk between zero and the following two lowest levels of meat intake (1-19g and 20-39g daily), which were also significantly associated with rachitic and osteomalacic risk. There was no significant decline in relative risk at meat intakes above $60 \mathrm{~g}$ daily. Vitamin $\mathrm{D}$ and $\mathrm{Ca}$ intakes were not significant model variables. Total protein, egg and fish intakes were not significantly associated with rachitic or 
Table 3. Group 1: intakes of four dietary variables and daylight outdoor exposure (DOE) in Muslim (M) and Sikh/Hindu (S/H) osteomalacia cases and control groups

\begin{tabular}{|c|c|c|c|c|c|c|c|c|}
\hline \multirow[b]{3}{*}{ Variable } & \multicolumn{8}{|c|}{ Osteomalacia: groups } \\
\hline & \multicolumn{2}{|c|}{ Controls (M 51, S/H 21) } & \multicolumn{2}{|c|}{ All cases (M 5, S/H 14) } & \multirow[b]{2}{*}{$P^{*}$} & \multicolumn{2}{|c|}{ Severe cases $(\mathrm{M} \mathrm{0,S/H} \mathrm{6)}$} & \multirow[b]{2}{*}{$P^{*}$} \\
\hline & median & $\min -\max$ & median & $\min -\max$ & & median & $\min -\max$ & \\
\hline \multicolumn{9}{|c|}{ Meat $(\mathrm{g} / \mathrm{d})$} \\
\hline All & 49 & $0-181$ & 0 & $0-173$ & $<0.001$ & 0 & 0 & $<0.001$ \\
\hline M & 54 & $0-181$ & 84 & $14-173$ & 0.298 & - & - & - \\
\hline $\mathrm{S} / \mathrm{H}$ & 32 & $0-133$ & 0 & $0-30$ & 0.002 & 0 & 0 & 0.007 \\
\hline \multicolumn{9}{|c|}{ Fibre (g/d) } \\
\hline All & 22 & $9-48$ & 27 & $13-41$ & 0.086 & 31 & $17-41$ & 0.045 \\
\hline M & 22 & $9-48$ & 19 & $13-30$ & 0.557 & - & - & - \\
\hline $\mathrm{S} / \mathrm{H}$ & 25 & $9-39$ & 30 & $17-41$ & 0.110 & 31 & $17-41$ & 0.140 \\
\hline \multicolumn{9}{|c|}{$\mathrm{Ca}(\mathrm{mg} / \mathrm{d})$} \\
\hline All & 760 & $285-1582$ & 958 & $184-1580$ & 0.006 & 1047 & $872-1272$ & 0.003 \\
\hline $\mathrm{M}$ & 709 & $285-1228$ & 833 & $184-1090$ & 0.911 & - & - & - \\
\hline $\mathrm{S} / \mathrm{H}$ & 803 & $453-1582$ & 971 & $628-1580$ & $0 \cdot 186$ & 1047 & $872-1272$ & 0.140 \\
\hline \multicolumn{9}{|c|}{ Vitamin $D(\mu \mathrm{g} / \mathrm{d})$} \\
\hline All & 1.92 & $0.57-4.53$ & $1 \cdot 15$ & $0.32-3.99$ & 0.011 & 0.89 & $0.35-1.15$ & 0.003 \\
\hline M & 1.93 & $0.79-4.53$ & 1.81 & $1.10-3.99$ & 0.676 & - & - & - \\
\hline $\mathrm{S} / \mathrm{H}$ & 1.90 & $0.57-3.83$ & 1.01 & $0.32-2.47$ & 0.022 & 0.89 & $0.35-1.15$ & 0.036 \\
\hline \multicolumn{9}{|c|}{$\mathrm{DOE}(\mathrm{min} / \mathrm{d})$} \\
\hline All & 44 & $0-171$ & 24 & $0-92$ & 0.085 & 4.5 & $0-77$ & 0.009 \\
\hline M & 44 & $0-171$ & 18 & $4-34$ & 0.032 & - & - & - \\
\hline $\mathrm{S} / \mathrm{H}$ & 42 & $12-121$ & 26 & $0-92$ & 0.270 & 4.5 & $0-77$ & 0.008 \\
\hline
\end{tabular}

* Significance of case-control differences (Mann-Whitney $U$ test; two-tailed).

For details of subjects and procedures, see p. 984.

osteomalacic relative risk in this model (intakes tabulated in original studies; Henderson et al. 1987, 1990).

Group 1: osteomalacia model. Zero meat intake in strictly lactovegetarian women was the only significant independent dietary variable associated with all cases of osteomalacia (Table 5). Relative risks were not significant at all meat intakes above zero.
Fibre, $\mathrm{Ca}$ and vitamin D intakes were not significant model variables (intakes tabulated in original study; Henderson et al. 1990).

Group 2: rickets model. Zero and low meat intakes were significantly associated with all cases of nutritional rickets, as in the combined osteomalacia and rickets model; maximum relative risk was associated with zero meat intakes (Table 6). Relative

Table 4. Group 2: intakes of four dietary variables and daylight outdoor exposure (DOE) in Muslim (M) and Sikh/Hindu (S/H) rickets cases and control groups

\begin{tabular}{|c|c|c|c|c|c|c|c|c|}
\hline \multirow[b]{3}{*}{ Variable } & \multicolumn{8}{|c|}{ Rickets: groups } \\
\hline & \multicolumn{2}{|c|}{ Controls (M 15, S/H 26) } & \multicolumn{2}{|c|}{ All cases (M 14, S/H 29) } & \multirow[b]{2}{*}{$P^{*}$} & \multicolumn{2}{|c|}{ Severe cases $(\mathrm{M} \mathrm{10}, \mathrm{S} / \mathrm{H} 6)$} & \multirow[b]{2}{*}{$P^{*}$} \\
\hline & median & $\min -\max$ & median & $\min -\max$ & & median & $\min -\max$ & \\
\hline \multicolumn{9}{|c|}{ Meat $(\mathrm{g} / \mathrm{d})$} \\
\hline All & 44 & $0-171$ & 30 & $0-222$ & 0.017 & 21 & $0-210$ & 0.016 \\
\hline M & 61 & $7-171$ & 32 & $0-210$ & 0.057 & 31 & $0-210$ & 0.160 \\
\hline $\mathrm{S} / \mathrm{H}$ & 30 & $0-159$ & 21 & $0-222$ & 0.100 & 10 & $0-21$ & 0.003 \\
\hline \multicolumn{9}{|c|}{ Fibre (g/d) } \\
\hline All & 22 & $12-36$ & 24 & $13-56$ & 0.119 & 25 & $16-56$ & 0.041 \\
\hline M & 20 & $16-33$ & 25 & $17-56$ & 0.018 & 25 & $17-56$ & 0.019 \\
\hline $\mathrm{S} / \mathrm{H}$ & 22 & $12-36$ & 21 & $13-49$ & 0.692 & 23 & $16-43$ & 0.724 \\
\hline \multicolumn{9}{|c|}{$\mathrm{Ca}(\mathrm{mg} / \mathrm{d})$} \\
\hline All & 883 & $291-1506$ & 951 & $277-2161$ & 0.570 & 707 & $277-1110$ & 0.062 \\
\hline M & 803 & $530-1433$ & 706 & $335-1097$ & 0.234 & 669 & $335-1097$ & 0.062 \\
\hline $\mathrm{S} / \mathrm{H}$ & 934 & $291-1506$ & 1031 & $277-2161$ & 0.200 & 953 & $277-1110$ & 0.621 \\
\hline \multicolumn{9}{|c|}{ Vitamin D ( $\mu \mathrm{g} / \mathrm{d})$} \\
\hline All & 1.48 & $0.16-3.93$ & 1.46 & $0.32-4.53$ & 0.971 & 1.34 & $0.32-3.24$ & 0.356 \\
\hline M & 1.49 & $0.86-3.47$ & 1.83 & $0.90-3.24$ & 0.290 & 1.82 & $0.90-3.24$ & 0.495 \\
\hline $\mathrm{S} / \mathrm{H}$ & 1.27 & $0.16-3.93$ & 1.22 & $0.32-4.53$ & 0.680 & 0.49 & $0.32-0.84$ & $<0.001$ \\
\hline \multicolumn{9}{|c|}{$\mathrm{DOE}(\mathrm{min} / \mathrm{d})$} \\
\hline All & 84 & $34-261$ & 64 & $9-224$ & 0.003 & 59 & $9-224$ & 0.024 \\
\hline M & 65 & $34-261$ & 55 & $9-224$ & 0.230 & 55 & $9-224$ & 0.202 \\
\hline $\mathrm{S} / \mathrm{H}$ & 97 & $43-223$ & 68 & $29-114$ & 0.006 & 94 & $59-101$ & 0.641 \\
\hline
\end{tabular}

* Significance of case-control differences (Mann-Whitney $U$ test; two-tailed).

For details of subjects and procedures, see p. 984. 
Table 5. Groups 1 and 2: contributions of four dietary variables and daylight outdoor exposure (DOE) to the relative risks (RR) of all cases of rickets and osteomalacia and all cases of osteomalacia

\begin{tabular}{|c|c|c|c|c|c|c|}
\hline \multirow[b]{3}{*}{ Variable* $^{*}$} & \multicolumn{6}{|c|}{ Logistic regression models } \\
\hline & \multicolumn{3}{|c|}{ Osteomalacia \& rickets† (all cases 62, controls 113) } & \multicolumn{3}{|c|}{ Osteomalacia (all cases 19 , controls 72 ) } \\
\hline & $\mathrm{RR}$ & $(95 \% \mathrm{Cl}) \ddagger$ & $P$ & $\mathrm{RR}$ & $(95 \% \mathrm{Cl}) \ddagger$ & $P$ \\
\hline \multicolumn{7}{|l|}{ Meat $(\mathrm{g} / \mathrm{d})$} \\
\hline 0 & $29 \cdot 8$ & $(4 \cdot 96,181)$ & $<0.001$ & $9 \cdot 28$ & $(1.07,80.6)$ & 0.043 \\
\hline $1-19$ & 4.43 & $(1 \cdot 12,17 \cdot 6)$ & 0.034 & 0.68 & $(0 \cdot 06,, 8 \cdot 45)$ & 0.767 \\
\hline $20-39$ & 3.96 & $(1 \cdot 23,12 \cdot 7)$ & 0.021 & $1 \cdot 15$ & $(0.15,8.80)$ & 0.894 \\
\hline $40-59$ & $1 \cdot 25$ & $(0.32,4.98)$ & 0.747 & 0.28 & $(0.03,2.97)$ & 0.288 \\
\hline $60+$ & 1.00 & (base) & & 1.00 & (base) & \\
\hline Fibre (g/d) & 1.53 & $(1.01,2 \cdot 32)$ & 0.043 & 1.01 & $(0.53,1.93)$ & 0.975 \\
\hline $\mathrm{Ca}(\mathrm{mg} / \mathrm{d})$ & 0.88 & $(0.57,1.35)$ & 0.565 & 0.95 & $(0.49,1.85)$ & 0.887 \\
\hline Vitamin $D(\mu \mathrm{g} / \mathrm{d})$ & 1.37 & $(0.84,2.23)$ & 0.207 & 0.88 & $(0.41,1.89)$ & 0.735 \\
\hline $\operatorname{DOE}(\min / \mathrm{d})$ & 0.33 & $(0.17,0.66)$ & $<0.001$ & - & - & - \\
\hline
\end{tabular}

* Based on average daily dietary intakes and DOE derived from $7 \mathrm{~d}$ records.

† Model based on 151 cases and controls (DOE data unavailable from twenty-four women and children).

$\ddagger \mathrm{RR}$ of osteomalacia/rickets associated with independent variables (exponential $\beta$ in logistic model).

For details of subjects and procedures, see p. 984

risk respectively approached and attained significance at the $1-$ $19 \mathrm{~g}$ and $20-39 \mathrm{~g}$ levels of daily meat intake. There was no further reduction in relative risk at meat intakes above $60 \mathrm{~g}$ daily. As in the osteomalacia model, fibre, $\mathrm{Ca}$ and vitamin D intakes were not significant model variables (intakes tabulated in original study; Henderson et al. 1987).

Group 2: severe rickets model. In the smaller severe rickets sample, relative risks associated with zero and low meat intakes were of similar magnitude to those in the all-cases rickets model but did not attain statistical significance (Table 6). Dietary fibre and $\mathrm{Ca}$ intakes showed respectively significant positive and negative associations with the relative risk of severe rickets. Vitamin D intake was not a significant model variable.

\section{Trends in dietary variables by religious affiliation}

Group 1: osteomalacia study. There were significant reductions in median meat and vitamin D intakes between the control and all-cases and severe-cases groups of Sikh/Hindu women. There were no significant differences between controls and five Muslim women with osteomalacia (Table 3).

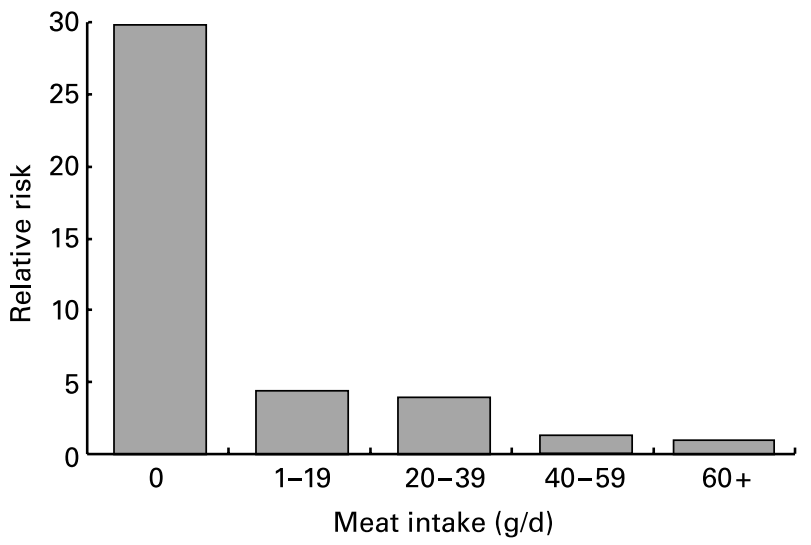

Fig. 1. Relationship of meat intakes to the independent relative risk of osteomalacia and rickets in 151 cases and controls. For details of logistic regression models, see Table 5 .
There were no significant univariate correlations between fibre intakes and serum $\mathrm{Ca}$, phosphate and alkaline phosphatase levels in all women, or in Muslim or Sikh/Hindu women (combined cases and controls). In contrast, there were significant negative correlations between meat intakes and serum alkaline phosphatase levels in all women and in predominately lactovegetarian Sikh/ Hindu women but not in omnivore Muslim women (Table 7).

Group 2: rickets study. There were significant reductions in median meat and vitamin D intakes between the control and severe-cases groups of Sikh/Hindu children. Significant increases in median fibre intakes between the control and the all-cases and severe-cases groups of Muslim children were accompanied by non-significant reductions in median meat and $\mathrm{Ca}$ intakes (Table 4).

In all children (combined cases and controls), there was a significant negative univariate correlation between fibre intakes and serum phosphate levels. In Muslim children, there were respectively significant negative and positive correlations between fibre intakes and serum phosphate and alkaline phosphatase levels; a negative correlation with serum $\mathrm{Ca}$ approached significance. In Sikh/Hindu children, there was a significant negative correlation between fibre intakes and serum phosphate levels. There were significant positive correlations between meat intakes and serum phosphate levels in all, Muslim and Sikh/Hindu children (Table 8).

\section{Discussion}

In 1918, Mellanby described 'the part played by an accessory factor in the production of experimental rickets'. He also concluded that meat was highly protective against rickets in puppies and considered its action unrelated to that of his 'accessory food factor', subsequently identified as vitamin D (Mellanby, 1918, 1921). He later discovered an 'anticalcifying factor' in oatmeal in the same animal model, which he identified as phytic acid (Mellanby, 1949). The present review confirms and amplifies Mellanby's findings with regard to dietary factors other than vitamin D in women and children.

Endogenous vitamin D deficiency (low serum $25(\mathrm{OH}) \mathrm{D}_{3}$ ) is a necessary but insufficient cause of what may be justifiably 
Table 6. Group 2: Contributions of four dietary variables to the relative risks (RR) of all cases of rickets and severe cases of rickets

\begin{tabular}{|c|c|c|c|c|c|c|}
\hline \multirow[b]{3}{*}{ Variable* $^{\star}$} & \multicolumn{6}{|c|}{ Logistic regression models } \\
\hline & \multicolumn{3}{|c|}{ Rickets (all cases 43 , controls 41 ) } & \multicolumn{3}{|c|}{ Severe rickets (all cases 16 , controls 41 ) } \\
\hline & $\mathrm{RR}$ & $(95 \% \mathrm{Cl}) \dagger$ & $P$ & $\mathrm{RR}$ & $(95 \% \mathrm{Cl}) \dagger$ & $P$ \\
\hline \multicolumn{7}{|l|}{ Meat (g/d) } \\
\hline 0 & $18 \cdot 4$ & $(1 \cdot 61,209)$ & 0.019 & $20 \cdot 7$ & $(0 \cdot 72,597)$ & 0.078 \\
\hline $1-19$ & 4.44 & $(0 \cdot 98,20 \cdot 1)$ & 0.053 & $5 \cdot 36$ & $(0 \cdot 60,47 \cdot 8)$ & 0.133 \\
\hline $20-39$ & 4.50 & $(1 \cdot 24,16 \cdot 3)$ & 0.022 & $3 \cdot 74$ & $(0.47,29.8)$ & 0.212 \\
\hline $40-59$ & 1.46 & $(0.27,7.94)$ & 0.665 & 1.04 & $(0.04,27.5)$ & 0.981 \\
\hline $60+$ & 1.00 & (base) & & 1.00 & (base) & \\
\hline Fibre $(g / d)$ & 1.47 & $(0.99,2 \cdot 19)$ & 0.056 & $2 \cdot 62$ & $(1 \cdot 20,5 \cdot 71)$ & 0.016 \\
\hline $\mathrm{Ca}(\mathrm{mg} / \mathrm{d})$ & 0.80 & $(0.51,1.25)$ & 0.332 & 0.32 & $(0.14,0.76)$ & 0.010 \\
\hline Vitamin D $(\mu \mathrm{g} / \mathrm{d})$ & 1.33 & $(0.79,2 \cdot 24)$ & 0.282 & 0.92 & $(0 \cdot 38,2 \cdot 23)$ & 0.846 \\
\hline
\end{tabular}

* Based on average daily dietary intakes from $7 \mathrm{~d}$ records.

†RR of rickets associated with independent variables (exponential $\beta$ in logistic model).

For details of subjects and procedures, see p. 984.

Table 7. Group 1: univariate correlations between dietary fibre, meat intakes and serum corrected calcium, phosphate and alkaline phosphatase in Muslim and Sikh/Hindu osteomalacia cases and control groups

\begin{tabular}{|c|c|c|c|c|c|c|}
\hline \multirow[b]{2}{*}{ Groups (cases \& controls) } & \multicolumn{2}{|c|}{$\mathrm{Ca}(\mathrm{mmol} / \mathrm{l})$} & \multicolumn{2}{|c|}{ Phosphate (mmol/l) } & \multicolumn{2}{|c|}{ Alkaline phosphatase (IU/I) } \\
\hline & $r^{*}$ & $P$ & $r^{*}$ & $P$ & $r^{*}$ & $P$ \\
\hline \multicolumn{7}{|l|}{ Fibre $(g / d)$} \\
\hline All women $(n 91) \dagger$ & -0.147 & 0.185 & -0.064 & 0.553 & 0.098 & 0.360 \\
\hline Muslim women ( $n$ 56) & -0.086 & 0.541 & $0 \cdot 104$ & 0.455 & -0.025 & 0.854 \\
\hline Sikh/Hindu women ( $n$ 35) & -0.215 & 0.254 & -0.247 & $0 \cdot 159$ & 0.175 & 0.323 \\
\hline \multicolumn{7}{|l|}{ Meat $(g / d)$} \\
\hline All women $(n$ 91)† & $0 \cdot 131$ & 0.237 & 0.129 & 0.231 & -0.287 & 0.006 \\
\hline Muslim women ( $n$ 56) & -0.027 & 0.845 & 0.042 & 0.764 & 0.066 & 0.632 \\
\hline Sikh/Hindu women ( $n$ 35) & 0.273 & 0.144 & 0.210 & 0.234 & -0.496 & 0.003 \\
\hline
\end{tabular}

* Spearman non-parametric correlation coefficient (two-tailed)

†Values of fourteen osteomalacic women modified by previous treatment with vitamin D.

For details of subjects and procedures, see p. 984

Table 8. Group 2: univariate correlations between dietary fibre, meat intakes and serum corrected calcium, phosphate and alkaline phosphatase in Mus$\lim \&$ Sikh/Hindu rickets cases and control groups

\begin{tabular}{|c|c|c|c|c|c|c|}
\hline \multirow[b]{2}{*}{ Groups (cases \& controls) } & \multicolumn{2}{|c|}{$\mathrm{Ca}(\mathrm{mmol} / \mathrm{l})$} & \multicolumn{2}{|c|}{ Phosphate (mmol/l) } & \multicolumn{2}{|c|}{ Alkaline phosphatase (IU/l) } \\
\hline & $r^{*}$ & $P$ & $r^{*}$ & $P$ & $r^{*}$ & $P$ \\
\hline \multicolumn{7}{|l|}{ Fibre (g/d) } \\
\hline All children $(n$ 84) $\dagger$ & -0.127 & 0.251 & -0.282 & 0.010 & 0.179 & 0.104 \\
\hline Muslim children ( $n$ 29) & -0.369 & 0.053 & -0.394 & 0.038 & 0.533 & 0.004 \\
\hline Sikh/Hindu children ( $n$ 55) & -0.023 & 0.886 & -0.275 & 0.042 & 0.046 & 0.738 \\
\hline \multicolumn{7}{|l|}{ Meat $(g / d)$} \\
\hline All children $(n$ 84)† & 0.074 & 0.504 & 0.332 & 0.002 & -0.154 & 0.164 \\
\hline Muslim children ( $n$ 29) & -0.049 & 0.803 & 0.443 & 0.018 & -0.076 & 0.701 \\
\hline Sikh/Hindu children ( $n$ 55) & 0.116 & 0.399 & 0.282 & 0.037 & -0.128 & 0.352 \\
\hline
\end{tabular}

* Spearman non-parametric correlation coefficient (two-tailed).

†Values of five rachitic children modified by previous treatment with vitamin D.

For details of subjects and procedures, see p. 984.

termed nutritional rickets and osteomalacia (Pietrek et al. 1976). In the osteomalacia case-control study, excluding patients with previously treated rickets and osteomalacia, $58 \%$ of Asian women had vitamin D insufficiency (serum $25(\mathrm{OH}) \mathrm{D} 5-15 \mathrm{ng} / \mathrm{ml})$ and $16 \%$ severe vitamin $\mathrm{D}$ deficiency (serum $25(\mathrm{OH}) \mathrm{D}<5 \mathrm{ng} / \mathrm{ml}$ ). In the rickets study, $45 \%$ of
Asian children had vitamin D insufficiency and $40 \%$ severe vitamin $\mathrm{D}$ deficiency.

The results of the present study have clarified the three unresolved issues raised earlier. The major statistically independent dietary variables associated with all cases of rickets and osteomalacia were zero or low intakes of meat and high intakes of dietary 
fibre (which is highly correlated with dietary phytate). The relative importance of these dietary risk factors appeared related to age, growth-related demand for $\mathrm{Ca}$ and vitamin $\mathrm{D}$, dietary pattern (lactovegetarian or omnivore), religious affiliation and available $\mathrm{Ca}$ intakes.

To address the first issue, there was a curvilinear relationship between meat intake and combined rachitic and osteomalacic relative risk. The latter fell steeply from zero to the $40-59 \mathrm{~g}$ meat intake level; relative risk did not fall further at meat intakes above $60 \mathrm{~g}$ daily. Meat intake appeared to reduce osteomalacic risk more effectively in women than in children; relative risk fell to insignificant levels at all meat intakes above zero in the former group.

To address the second issue, in a largely unfortified diet, dietary vitamin D intake was unrelated to rachitic or osteomalacic risk. Assuming an average revised meat vitamin D content of about $0.7 \mu \mathrm{g}$ vitamin $\mathrm{D} / 100 \mathrm{~g}$ meat, large reductions in the relative risk of osteomalacia and rickets between meat intakes of zero and the 20-39g daily intake level were associated with an average daily increase of less than $0.25 \mu \mathrm{g}(10 \mathrm{IU})$ vitamin $\mathrm{D}$ (Chan et al. 1995). It seems improbable that this small increase could account for such large reductions in rachitic and osteomalacic relative risk, particularly since total dietary vitamin D intake was not associated with rachitic or osteomalacic risk in any of the four logistic models. However, there must be some uncertainty about the use of the 'five times' formula in estimating the equivalent biological potency of the $25(\mathrm{OH}) \mathrm{D}$ content of meat in man, since this estimate was derived from an in vitro $\mathrm{Ca}$ transport assay in the rat.

At present, the mechanism by which small amounts of meat reduce rachitic and osteomalacic risk remains uncertain. Meat enhances the absorption of haem and non-haem Fe (Hallberg et al. 1979), and sideropenia and Fe-deficiency anaemia commonly accompany lactovegetarian rickets and osteomalacia (Grindulis et al. 1986). It is conceivable that a comparable interaction between meat and enteral vitamin D metabolites may occur during meat digestion, increasing the efficiency of the latter's absorption or reabsorption. A report that an oral Fe supplement significantly increased serum $25(\mathrm{OH}) \mathrm{D}$ levels in Fe-deficient Israeli children with apparently adequate solar exposure may link the factor(s) in meat responsible for both the enhancement of $\mathrm{Fe}$ absorption and the reduction of rachitic and osteomalacic risk (Heldenberg et al. 1992).

Since red and white meats were both consumed by women and children in the present study, it was impossible to assess their relative potencies in reducing disease risk. It is also uncertain whether the absence of significant independent associations between fish and egg intakes and rachitic and osteomalacic relative risk reflects lower intakes of these foods in the present study compared with meat or lower biological effectiveness.

The dominant dietary pattern associated with low or absent meat intakes in the osteomalacia (Group 1) and rickets (Group 2) dietary surveys was lactovegetarianism in Sikh and Hindu women and children. These findings are consistent with previous evidence that severe Asian osteomalacia is confined to strictly lactovegetarian Sikh and Hindu Asian women (Stamp et al. 1980; Dandona et al. 1985). Lactovegetarian adult British Asians, mainly women, have significantly lower serum 25(OH)D levels than omnivore Asians, although Sikh and Hindu women do not 'cover up' as much as their omnivore Muslim counterparts (Dent \& Gupta, 1975; Hunt et al. 1976; Finch et al. 1992). These findings reinforce the hypothesis that the mechanism by which meat reduces rachitic and osteomalacic risk involves an interaction with the vitamin D economy, possibly, as noted earlier, within the alimentary tract. There is no current evidence that meat intakes independently modify $\mathrm{Ca}$ or $\mathrm{P}$ absorption from the gut or have an independent effect on bone metabolism.

Total fat intakes were similar in cases and controls and in omnivore and lactovegetarian subjects in the Group 1 and Group 2 studies. Differences in the absorption of fat-soluble vitamins in lactovegetarian and omnivore subjects due to variations in fat intake are improbable (Henderson et al. 1987, 1990).

A previous hypothesis that dietary protein may stimulate the synthesis of serum $25(\mathrm{OH}) \mathrm{D}$ via the hepatic mixed oxidase system is unsupported by lack of a significant independent association between total protein intake and rachitic or osteomalacic relative risk in the present study (Dollery et al. 1977). White and Asian omnivore and lactovegetarian women given a single oral dose of $1.25 \mathrm{mg}$ vitamin $\mathrm{D}_{2}$ without food had similar clearance rates of serum $25(\mathrm{OH}) \mathrm{D}_{2}$ and $1,25(\mathrm{OH})_{2} \mathrm{D}_{2}$ (JL Berry, JB Henderson, D Hole, S Mylchreest, M Davies, AP Mee, EB Mawer and MG Dunnigan, unpublished results). This evidence is also inconsistent with an alternative hypothesis that increased 24,25-hydroxylase activity in skin fibroblasts in Asian compared with white adults may result in more rapid degradation of serum 25(OH)D and 1,25(OH)D in the former group (Awumey et al. 1998). Intermediary vitamin D metabolism appears similar in lactovegetarian and omnivore Asian and white women.

To address the third issue posed earlier, the meat and fibre risk factors were related to growth, sex and religious affiliation.

Multivariate logistic regression showed no significant association between fibre intakes and osteomalacic relative risk. There were also no univariate correlations between fibre intakes and serum $\mathrm{Ca}$, phosphate or alkaline phosphatase levels in Asian women in the Group 1 osteomalacia study. The absence of growth-related demand for $\mathrm{Ca}$ and vitamin $\mathrm{D}$ appears to attenuate fibre risk. Clinical nutritional osteomalacia is rare in men.

In contrast, as noted previously, high fibre intakes were independently associated with severe cases of rickets in omnivore Muslim children in the first dietary survey (Dunnigan \& Smith, 1965; Dunnigan et al. 1976; Robertson et al. 1982). In this study there were significant negative univariate correlations between fibre intakes and both serum $\mathrm{Ca}(r 0.741, P<0.002)$ and serum phosphate ( $r$ 0.606, $P<0.017$ ), and a significant positive correlation with serum alkaline phosphatase $(r 0.717, P<0 \cdot 001)$.

High fibre intakes were also independently associated with severe cases of rickets in the second Group 2 rickets dietary survey; analysis by religious affiliation indicated that this risk factor was mainly derived from omnivore Muslim children. The presence of significant correlations between fibre intakes and both serum phosphate and alkaline phosphatase levels in this group provides further evidence for the pathogenic role of high fibre intakes in children of both sexes, particularly at puberty when growth-related demand for dietary $\mathrm{Ca}$ is high. In this setting, Ca binding by dietary fibre and phytate further constrains limited available dietary $\mathrm{Ca}$. In Muslim adolescents with severe rickets, low $\mathrm{Ca}$ intakes reflected low milk intakes, which were replaced by high-carbohydrate beverages. The absence of comparably significant correlations between fibre intakes and biochemical evidence of osteomalacia in Sikh and Hindu children consuming a high-Ca lactovegetarian diet suggests that high fibre intakes were less pathogenic in this group.

These findings are consistent with previous studies linking high intakes of wholemeal and high-extraction cereals with nutritional 
rickets in Asian and white children (Ford et al. 1972b; Wills et al. 1972; Robertson et al. 1981). A causal link between low Ca availability and endogenous vitamin D deficiency has been provided by evidence that low $\mathrm{Ca}$ intakes or Ca malabsorption result in secondary hyperparathyroidism, raised serum $1,25(\mathrm{OH}) \mathrm{D}$ and accelerated inactivation of serum $25(\mathrm{OH}) \mathrm{D}$ to inactive biliary metabolites (Clements et al. 1987).

In summary, dietary patterns related to culture, religion, age, available $\mathrm{Ca}$ intake and growth-related demand for $\mathrm{Ca}$ and vitamin $\mathrm{D}$ determined the operation of the low meat and high fibre risk factors associated with nutritional rickets and osteomalacia in the three weighed intake dietary surveys reviewed earlier. The absence of the low meat risk factor from the first rickets study of omnivore Muslim children, the attenuation of the high fibre risk factor in lactovegetarian Sikh and Hindu children in the second rickets study and its absence from the osteomalacia study are explained by these observations.

The model of dietary risk factors associated with nutritional late rickets and osteomalacia in the British Asian community may be relevant in other settings. Comparisons are handicapped by the absence of comparable multivariate analyses of dietary risk factors associated with cases of nutritional rickets and osteomalacia in the medical literature. Nevertheless, provisional comparisons may be drawn between the present risk factor model and dietary patterns associated with infantile and toddler rickets and with nutritional osteomalacia, predominantly in the elderly, irrespective of ethnicity.

Examination of the case records of seventy-seven hospital discharges with nutritional osteomalacia from Scottish hospitals over a 3-year period (1987-1989) indicated major nutritional deficiencies and malnutrition in most patients; all but six were over 70 years of age (Dunnigan \& Henderson, 1997). Where adequate documentation was available, the diets consisted predominantly of bread, biscuits, crisps and cake. Little meat, fish or eggs were consumed and milk was taken mainly in tea. The low meat and $\mathrm{Ca}$ risk factors identified in the present review could be identified in most of these housebound frail patients, living alone and coping with mental and physical handicaps.

Historically, and at present, available accounts of infantile and toddler rickets are associated with late weaning and the consumption of a high-Ca lactovegetarian diet up to about 2 years of age. Apart from milk, the diet typically contained low-fibre cereals (wheat, rice and oatflour), vegetables and a range of refined carbohydrate foods (Corry Mann, 1922; Mughal et al. 1999). The structure of this diet, apart from its low fibre content, resembles the Asian lactovegetarian diet consumed by the Sikh and Hindu women and children in the present review. In particular, the absence of animal foods, particularly meat and meat products, appears the sole dietary risk factor associated with lactovegetarian infantile and toddler rickets when exposure to UV radiation is limited and dietary vitamin $\mathrm{D}$ supplementation is absent or has been discontinued. Infantile and toddler rickets remain a significant problem in the British Asian population, in less developed economies and in ethnic minorities in several developed economies. A common factor in these settings is late weaning to a lactovegetarian diet up to at least 2 years of age (Wilton, 1995; Karrar, 1998; Bloc et al. 2000; Row, 2001; Shaw \& Pal, 2002; Wharton \& Bishop, 2003; Weisberg et al. 2004).

The present risk factor model of lactovegetarian rickets and osteomalacia suggests that the consumption of small quantities of meat and meat products would reduce or abolish the risk of clinical rickets. This evidence is consistent with the virtual disappearance of toddler rickets from the indigenous Scottish population since the introduction of early weaning at about 4 months of age in the last 40 years (Dunnigan \& Henderson, 1997). Of a sample of British white children aged 1.5-2.5 years consuming a median $30 \mathrm{~g}$ meat daily $81 \%$ did not receive a vitamin D supplement. Their median vitamin D intake was only $1 \mu \mathrm{g}$ daily (40 IU; Gregory et al. 1995). Despite this, rickets is rare in the indigenous white population of the UK. Personal communication with health visitors currently involved with the Glasgow Asian community indicates that the mothers of a small number of mainly Muslim Asian children with toddler rickets and Fe-deficiency anaemia also practise late weaning with an exclusively lactovegetarian diet.

Validation of the risk factor model of nutritional rickets and osteomalacia derived from the Glasgow Asian community in other settings requires case-control studies based on comparably accurate measurements of dietary intake and outdoor exposure. This information is currently unavailable. With these reservations, the present model suggests that the prevention of infantile and toddler rickets (but not hypovitaminosis D) in the settings noted earlier would be achieved by advocating transition from a lateweaning cereal-based lactovegetarian diet to a meat-containing omnivore diet at 4-6 months of age. If this change in feeding practice remains unacceptable for cultural or religious reasons, vitamin D supplementation remains essential.

\section{Acknowledgements}

The case-control studies and statistical analyses were funded by grants from the Biomedical Research Committee of the Scottish Home and Health Department, Greater Glasgow Health Board's Research Support Group and the Food Standards Agency (Project 5018). We are indebted to the women and children of the Glasgow Asian Community who made the studies possible.

\section{References}

Awumey EM, Mitra DA, Hollis BW, Kumar R \& Bell NH (1998) Vitamin D metabolism in Asian Indians in the southern United States: a clinical research center study. J Clin Endocrinol Metab 83, 169-173.

Bloc BH, Grant CG, McNeil AR \& Reid IR (2000) Characteristics of children with florid vitamin D deficient rickets in the Auckland region in 1998. N Z Med J 113, 374-376.

Chan W, Brown J, Lee SM \& Buss DH (1995) Meat, Poultry and Game. Fifth Supplement to 5th edition of McCance and Widdowson's The Composition of Foods, pp. 152-153. Cambridge/London: The Royal Society of Chemistry/Ministry of Agriculture, Fisheries and Food.

Clements MR, Johnson L \& Fraser DR (1987) A new mechanism for induced vitamin D deficiency in calcium deprivation. Nature 324, $62-65$.

Corry Mann H (1922) Rickets. The Relative Importance of Environment and Diet as Factors of Causation: An Investigation in London. Medical Research Council Special Report Series no. 68. London: HM Stationery Office.

Dandona P, Okonofua F \& Clements RV (1985) Osteomalacia presenting as pathological fractures during pregnancy in women of high socioeconomic class. Br Med J 290, 837-838.

Dent CE (1974) Definition of osteomalacia. Lancet i, 805.

Dent CE \& Gupta MM (1975) Plasma 25-hydroxyvitamin D levels during pregnancy in Caucasians and in vegetarian and non-vegetarian Asians. Lancet ii, 1057-1060.

Dollery CT, Fraser HS, Davies D \& McIntyre I (1977) Vitamin D status in different subgroups of British Asians. Br Med J 1, 104. 
Dunnigan MG, Glekin BM, Henderson JB, McIntosh WB, Sumner D \& Sutherland JR (1985) Prevention of rickets in Asian children: assessment of the Glasgow campaign. Br Med J 291, 239-242.

Dunnigan MG \& Henderson JB (1997) An epidemiological model of privational rickets and osteomalacia. Proc Nutr Soc 56, 939-956.

Dunnigan MG, McIntosh WB \& Ford JA (1976) Rickets in Asian immigrants. Lancet i, 1346.

Dunnigan MG, Paton JPJ, Haase S, McNicol GW, Gardner MD \& Smith CM (1962) Late rickets and osteomalacia in the Pakistani community in Glasgow. Scot Med J 7, 159-167.

Dunnigan MG \& Smith CM (1965) The aetiology of late rickets in Pakistani children in Glasgow. Report of a diet survey. Scot Med J 10, 1-9.

Finch PJ, Ang L, Colston KW, Nisbet J \& Maxwell JD (1992) Blunted seasonal variation in serum 25-hydroxyvitamin $\mathrm{D}$ and increased risk of osteomalacia in vegetarian London Asians. Eur J Clin Nutr 46, 509-515.

Ford JA, Colhoun EM, McIntosh WB \& Dunnigan MG (1972a) Rickets and osteomalacia in the Glasgow Pakistani community, 1961-1971. Br Med J 2, 677-680.

Ford JA, Colhoun EM, McIntosh WB \& Dunnigan MG (1972b) Biochemical response of late rickets and osteomalacia to a chapatti-free diet. Br Med J 3, 446-447.

Ford JA, Davidson DC, McIntosh WB, Fyfe WM \& Dunnigan MG (1973) Neonatal rickets in Asian immigrant population. $\mathrm{Br}$ Med J 3, 211-212.

Fraser DR (1995) Vitamin D. Lancet 345, 104-108.

Gopalan C, Sastri BR \& Balasubramanian SC (1971) Nutritive Value of Indian Foods. Hyderabad: National Institute of Nutrition.

Gregory JR, Collins DL, Davies PSW, Hughes JM \& Clarke PC (1995) National Diet \& Nutrition Survey: Children Aged $1 \frac{1}{2}$ to $4 \frac{1}{2}$ years, vol. 1. Report of the Diet and Nutrition Survey. London: HM Stationery Office.

Grindulis H, Scott PH, Belton NR \& Wharton BA (1986) Combined deficiency of iron and vitamin D in Asian toddlers. Arch Dis Child 61, 843-848.

Hallberg L, Bjorn-Rasmussen E, Howard L \& Rossander L (1979) Dietary heme iron absorption. A discussion of possible mechanisms for the absorption-promoting effect of meat and for the regulation of iron absorption. Scand J Gastroenterol 14, 769-779.

Heldenberg D, Tenenbaum G \& Weisman Y (1992) Effect of iron on serum 25-hydroxyvitamin D and 24,25-dihydroxyvitamin D concentrations. Am J Clin Nutr 56, 533-536.

Henderson JB, Dunnigan MG, McIntosh WB, Abdul-Motaal AA, Gettinby G \& Glekin BM (1987) The importance of limited exposure to ultraviolet radiation and dietary factors in the aetiology of Asian rickets: a risk factor model. $Q$ J Med 63, 413-425.

Henderson JB, Dunnigan MG, McIntosh WB, Abdul-Motaal A \& Hole D (1990) Asian osteomalacia is determined by dietary factors when exposure to ultraviolet radiation is restricted: a risk factor model. Q J Med 76, 923-933.
Holmes AM, Enoch BA, Taylor JL \& Jones ME (1973) Occult rickets and osteomalacia amongst the Asian immigrant population. $Q \mathrm{~J}$ Med 42, $125-149$.

Hunt SP, O'Riordan JLH, Windo J \& Truswell AS (1976) Vitamin D status in different subgroups of British Asians. Br Med J 2, 1351-1354.

Iqbal SJ, Kaddam I, Wassif W, Nichol F \& Walls J (1994) Continuing clinically severe vitamin D deficiency in Asians in the UK (Leicester). Postgrad Med J 70, 708-714.

Karrar ZA (1998) Vitamin D deficiency rickets in developing countries. Ann Trop Paediatr 18, Suppl., 89-92.

Lawson DEM (1979) Dietary vitamin D. Lancet ii, 1021.

Mellanby E (1918) The part played by an 'accessory factor' in the production of experimental rickets. Proc Physiol Soc January 26, xi-xii.

Mellanby E (1921) Experimental Rickets. Medical Research Council Special Report Series no. 61. London: HM Stationery Office.

Mellanby E (1949) Rickets-producing and anti-calcifying action of phytate. J Physiol 109, 488-533.

Mughal MZ, Salama H, Greenaway T, Laing I \& Mawer EB (1999) Lesson of the week: florid rickets associated with prolonged breast feeding without vitamin D supplementation. Br Med J 318, 39-40.

Paul AA \& Southgate DAT (1978) McCance and Widdowson's The Composition of Foods, 4th ed. London: HM Stationery Office.

Pietrek J, Windo J, Preece MA, O'Riordan JL, Dunnigan MG, McIntosh WB \& Ford JA (1976) Prevention of vitamin D deficiency in Asians. Lancet i, 1145-1148.

Robertson I, Ford JA, McIntosh WB \& Dunnigan MG (1981) The role of cereals in the aetiology of nutritional rickets: the lesson of the Irish National Nutrition Survey 1944-8. Br J Nutr 45, 17-32.

Robertson I, Glekin BM, Henderson JB, McIntosh WB, Lakhani A \& Dunnigan MG (1982) Nutritional deficiencies among ethnic minorities in the United Kingdom. Proc Nutr Soc 41, 243-256.

Row PM (2001) Why is rickets resurgent in the USA? Lancet 357, 1100.

Shaw NJ \& Pal BR (2002) Vitamin D deficiency in UK Asian families: activating a new concern. Arch Dis Child 86, 147-149.

Stamp TCB, Walker PG, Perry W \& Jenkins MB (1980) Nutritional osteomalacia and late rickets in Greater London 1974-79: clinical and metabolic studies in 45 patients. Clin Endocrin Metab 9, 81-105.

Tanaka Y, Frank H \& De Luca HF (1973) Relative values for antirachitic activity as assessed by a calcium transport assay in the rat. Endocrinology 92, 417-422.

Weisberg P, Scanlon KS, Li R \& Cogswell ME (2004) Nutritional rickets among children in the United States: review of cases reported between 1986 and 2003. Am J Clin Nutr 80, 1697S-1705S.

Wharton B \& Bishop N (2003) Rickets. Lancet 362, 1389-1400.

Wills MR, Day RC, Phillips JB \& Bateman EC (1972) Phytic acid and nutritional rickets in immigrants. Lancet i, 771-773.

Wilton P (1995) Cod liver oil, vitamin D and the fight against rickets. Can Med Assoc J 153, 740-741. 